\title{
Letter
}

\section{Discussion of 'Influence of diaphragm wall installation on the numerical analysis of deep excavation', by Burlon S., Mroueh H. \& I. Shahrour}

In their paper, the Authors address the important issue of predicting the effects of the installation procedure on the response of excavations supported by embedded retaining walls. Most past work on installation effects, including full-scale monitoring of structures, centrifuge testing and numerical modelling, has concentrated on the case of heavily overconsolidated deposits [1-8]. More recently, the cases of installation of diaphragm walls in sand and soft clay, with initially low values of the coefficient of earth pressure at rest, $K_{0}$, have been examined numerically [9-12].

The core of the numerical work is devoted to an initial value of $K_{0}=1$, comparing the results obtained from 'wished in place' and 'wall installation modelled' analyses, both in plane strain (2D) and three-dimensional (3D) conditions. Part of the work deals with the effects of the initial value of $K_{0}$ on the results.

This discussion addresses a number of issues that the writers find not very clear, as detailed in the following.

\section{PRESENCE OF WATER AND TYPE OF ANALYSIS}

The Authors state that the problem under examination is based on a construction site of a diaphragm wall realized in the north of France for a subway project in a homogeneous clay deposit of saturated Flanders clay. The soil parameters given in Figure 3 of the paper are clearly effective stress parameters $\left(c^{\prime}=26 \mathrm{kPa}, \varphi^{\prime}=25^{\circ}, \psi=10^{\circ}\right)$, with the only exception of $\gamma\left(=18.9 \mathrm{kN} / \mathrm{m}^{3}\right)$ that appears to be a total (saturated) unit weight. No information is provided on the water table position or on the type of analysis that was carried out (drained/undrained/consolidation analysis). Judging from the results, and particularly from the contact stress distributions plotted in Figure 8 of the paper, it appears that the Authors have worked in drained conditions using total stress, thus neglecting any possible excess pore water pressures generated by panel installation (although this is clearly an undrained process in saturated clay) or by the subsequent excavation stage. By contrast, Shafer \& Triantafyllidis [10] have clearly shown that significant excess pore water pressures are generated around the trench during wall installation, so that the prediction of the state of stress induced by the installation stage cannot be performed in drained conditions. Also during the excavation stage in a saturated clay, it is likely that significant excess pore water pressures would arise, and therefore excavation in front of the wall should be modelled either using a consolidation analyses, with realistic construction times, or by carrying out the prediction of the excess pore pressure in undrained conditions and then simulating the subsequent dissipation of excess pore water pressures.

\section{CONSTITUTIVE MODELLING}

The Authors use a linear-elastic perfectly plastic constitutive model for the soil (MC), with a nonassociated failure criterion, justifying this assumption with the lack of experimental data to calibrate more advanced constitutive models. We agree with the fact that advanced constitutive models should be used with caution in the engineering practice if there are not enough laboratory data both to calibrate the model constants and to interpret the numerical results. However, we believe that the 
predictive capabilities of any constitutive model, with reference to a given class of soil engineering problems, should be assessed in order to define a minimum level of complexity which guarantees a sufficient level of accuracy of the prediction [13].

The importance of including soil non linearity to obtain realistic predictions of ground movements around excavations has long been demonstrated [13-15]. While computed wall deflections appear to be rather insensitive to the adopted constitutive model, provided that soil stiffness parameters are appropriately adjusted, linear-elastic perfectly plastic models completely fail to predict the pattern and magnitude of ground settlements behind the excavation, which are of major concern when dealing with installation effects.

More specifically, a linear-elastic perfectly plastic model is not capable of capturing all the factors that govern the behaviour of the soil in the construction process that the complex numerical analysis proposed by the Authors is supposed to model. While the model may describe satisfactorily the 3D effects associated with the earth pressure redistribution induced into the surrounding soil during wall installation, it is surely incapable of describing at least two other relevant aspects of soil behaviour. In particular, the model: (i) does not take into account the dependence of the soil response on the recent stress history, which many authors have recognized as playing a crucial role on the behaviour of the wall-soil system [10-12, 16, 17]; (ii) the constant elastic parameters required to define the response of the model inside the elastic domain have to be calibrated with reference to a certain level of mobilized shear strain which, for the problem at hand, differs substantially between the installation stage and the main excavation stage.

\section{NUMERICAL STRATEGIES}

The Authors have assumed a perfect contact between the wall and the soil, thus implying that the cohesion at the soil wall interface is equal to $c^{\prime}=26 \mathrm{kPa}$. Such an assumption has significant implications on the correctness of the results when dealing with excavation problems, especially if a simple elastic perfectly plastic model is assumed for the soil. In fact, in this case, the stress release imposed by the main excavation stage induces excessive ground heave around the excavation. As a consequence, the assumption of perfect contact leads to unrealistic increments of the effective vertical stress in the soil elements adjacent to the wall and, concurrently, to an over prediction of the passive resistance in front of the wall. Moreover, with such a value of the cohesion, high tractions must be expected at the soil-wall interface - and along a significant part of the wall starting from the ground surface - as the retained soil moves towards the active limit states when the wall rotates. As a result, an unrealistic contact stress distribution is expected both behind and in front of the wall, which will affect eventually the behaviour of the wall during the main excavation stage, both in terms of displacements and internal forces. As a matter of fact, the shape of the deflected wall profiles plotted in Figures 16 and 17 reveals a change in curvature (and so a change in the sign of bending moment distribution), which would be hardly expected for a cantilevered retaining wall, and which is clearly due to the tractions acting on the upper part of the wall.

\section{MINOR REMARKS}

The procedure adopted for wall installation outlined in Figure 1 of the paper is not very clear, as it seems that in steps 2 and 3, the Authors have not applied the hydrostatic bentonite nor the fluid concrete pressure on the bottom of the trench. Moreover, the linear distribution of contact stress in step 3 is not consistent with that given in step 2. In fact, the results of the analyses given in Figure 4 of the paper show clearly that the distribution of contact stress after concrete setting is still bi-linear, i.e. the same as in step 2 of Figure 1.

Finally, the Authors have carried out a parametric study to assess the influence of the initial state of stress on the response of the wall by taking three different values of the coefficient of earth pressures at rest, and specifically $0.5,1$ and 1.5 . It is worthy to outline that $K_{0}$ depends on the stress history of the soil deposit, and thus on the overconsolidation ratio. Accordingly, to explore the effects of different 
values of $K_{0}$, the mechanical properties of the soil mass have to be modified in a consistent manner, but this aspect has not received adequate attention in the paper.

\section{RicCARDO CONTI SISSA, Trieste, Italy \\ LuCA DE SANCTIS Dip. per le Tecnologie Università di Napoli Parthenope, Naples, Italy \\ E-mail: luca.desanctis@uniparthenope.it}

Giulia M.B. VigGiani Dip. Ingegneria Civile Università di Roma Tor Vergata, Rome, Italy

\section{REFERENCES}

1. Symons IF, Carder DR. Stress changes in stiff clay caused by the installation of embedded retaining walls. In Retaining structures, Clayton (ed.). Thomas Telford: London, 1993; 227-236.

2. Lings ML, Nash DFT, Ng CWW, Boyce MD. Observed behaviour of a deep excavation in Gault clay: a preliminary appraisal, 1991. Proc. X ECSMFE, Florence, 2, 467-470.

3. Powrie W, Kantartzi C. Ground response during diaphragm wall installation in clay: centrifuge model tests. Geotechnique 1996; 46(4):725-739.

4. Richards DJ, Powrie W, Page JRT. Investigation of retaining wall installation and performance using centrifuge modelling techniques. Proceedings of the ICE - Geotechnical Engineering 1998; 131(3):163-170.

5. Gunn MJ, Clayton CRI. Installation effects and their importance in the design of earth retaining structures. Geotechnique 1992; 42(1):137-141.

6. Ng CWW. Effects of modelling wall installation on multi-staged excavations in stiff clays. Proc. $1^{\text {st }}$ Int. Conf. on 'Pre-failure Deformation of Geomaterials', Sapporo 1, 1994; 595-600.

7. Rampello S, Stallebrass SE, Viggiani GMB. Ground movements associated with excavations in stiff clays: current prediction capability. Proc. $2^{\text {nd }}$ Int. Symp. on the Geotechnics of Hard-Soils/Soft Rocks, Naples, vol. 3, 1998; $1527-1540$.

8. Gourvenec SM, Powrie W. 3D finite-element analysis of diaphragm wall installation. Geotechnique 1999; 49 (6):801-823.

9. Mayer PM, Gudehus G. Prediction of soil movement due to diaphragm wall construction. Geotechnical Special Publication No 2002; 116:696-712.

10. Shäfer N, Triantafyllidis T. Modelling of earth and water pressure development during diaphragm wall construction in soft clay. International Journal for Numerical and Analytical Methods in Geomechanics 2004; 28:1305-1326.

11. Shäfer N, Triantafyllidis T. The influence of the construction process on the deformation behaviour of diaphragm walls in soft clayey ground. International Journal for Numerical and Analytical Methods in Geomechanics 2006; 30(7):563-576.

12. Conti R, de Sanctis L, Viggiani GMB. Numerical modelling of installation effects for diaphragm walls in sand. Acta Geotechnica 2012; 7(3):219-237.

13. Viggiani G, Tamagnini C. Ground movements around excavation in granular soils: a few remarks on the influence of the constitutive assumptions on FE predictions. Mech Cohes Frict Mater 2000; 5(5):399-423.

14. Simpson B. Retaining structures: displacement and design. Geotechnique 1992; 42(4):541-576.

15. St. John HD, Potts DM, Jardine RJ, Higgins KG. Prediction and performance of ground response due to construction of a deep basement at 60 Victoria Embankment. Proc. Wroth Mem. Symp. on 'Predictive Soil Mechanics' (Houlsby \& Schofield eds.) Thomas Telford, London, 1993, 581-608.

16. Powrie W, Pantelidou H, Stallebrass SE. Soil Stiffness in stress paths relevant to diaphragm walls in clay. Geotechnique 1998; 48(4):483-494.

17. Stallebrass SE, Taylor RN. The development and evaluation of a constitutive model for the prediction of ground movements in overconsolidated clay. Geotechnique 1997; 47(2):235-253. 